\title{
LAS FUNCIONES DEL DERECHO DE DAÑOS EN LA SOCIEDAD DEL RIESGO
}

José Fernando Márquez*

Recibido: 09.09.2014

Aprobado: 20.09.2014

\section{RESUMEN}

La sociedad posindustrial coloca a la humanidad frente a múltiples riesgos. El derecho de daños, que crea las reglas para la atribución de responsabilidad por perjuicios económicos y personales, se enfrenta a los problemas que genera esta nueva realidad, y se ve obligado a actualizar los conceptos que la explican y las herramientas para solucionarlos. En este marco, la función preventiva del derecho de daños se torna prioritaria y constituye su principal tarea actual.

\section{PALABRAS CLAVE}

Riesgos - Responsabilidad - Daños - Prevención.

\section{ABSTRACT}

Postindustrial society places humanity in front of multiple risks. Tort law, which creats rules for the attribution of responsability for economic and personal damages, faces the problems generated by this new reality and is forced to update the concepts that explain the matterand tools to solve. In this framework, the preventive function of tort law, becomes a priority and is its current main task.

\section{KEY WORDS}

Risks - Responsability - Damages - Prevention.

\section{SUMARIO}

I. La sociedad posmoderna. II. La sociedad del riesgo. III. El derecho de daños frente a la sociedad del riesgo. IV. Hacia un derecho de daños consolidado.

\section{I.- LA SOCIEDAD POSMODERNA.}

1.- Se señalan dos hitos que marcaron el paso de la modernidad o sociedad industrial, al posmodernismo, modernidad tardía, segunda modernidad o sociedad postindustrial: la caída del muro de Berlín (1989) y la explosión de la central nuclear de Chernobyl (1986), a los que nosotros agregaremos la apertura de los protocolos de Internet para el uso generalizado del público (entre 1986 y 1990).

La caída del muro de Berlín produjo el fin de la división de los países en dos grandes bloques, para dar paso a la unificación a

* Abogado (Universidad Nacional de Córdoba, Argentina), Doctor en Derecho y Ciencias Sociales (Universidad Nacional de Córdoba, Argentina), Profesor Titular, por concurso, de las Cátedras de Derecho Privado VII (Derecho de Daños), Universidad Nacional de Córdoba, Argentina, y de Derecho Civil II (Obligaciones), Universidad Católica de Córdoba, Argentina. Profesor Honorario de la Universidad Femenina del Sagrado Corazón. Profesor Honorario de la Universidad Privada de Tacna. 
través de las reglas del mercado, en lo que se dio en llamar el Fin de la historia (Fukujama) ${ }^{1}$, como modo de patentizar la finalización de la dialéctica propia del capitalismo, para pregonar su triunfo definitivo.

La explosión de la central de Chernobyl expuso de manera dramática las consecuencias visibles de la modernidad y su modelo de utilización ilimitada de la ciencia y la tecnología para la apropiación de la naturaleza, mostrando al mundo miles de seres humanos muertos o mutilados y sus consecuencias para las generaciones futuras.

La generalización de la Internet generó la creación de la más extensa red de comunicaciones jamás concebida, interconectando a millones de personas, en tiempos reales, desde los lugares más remotos del planeta. La aldea global, imaginada por Marshall Mc Luhan², se hizo realidad.

2.- Se presenta una realidad social, económica, cultural, moral, jurídica, diferente, la llamada sociedad postindustrial.

Los científicos sociales vislumbran un nuevo orden mundial caracterizado, entre otros síntomas, por:
- El paso de una economía industrial a una economía de servicios y de consumo.

- La ruptura con el pasado y la tradición.

- La renovación de las formas tradicionales del arte, la cultura, el pensamiento y la organización social.

- El relativismo. El hombre basa su existencia en la pluralidad de opciones.

- La personalidad individual pierde sustentos firmes: es siempre un continuo, pues la identidad siempre es un proyecto inacabado ${ }^{3}$.

- Los medios masivos de comunicación se constituyen en centros de poder. Se pierde el concepto de autoridad, se desacraliza la política y desmitifican los líderes.

3. - Las ciencias sociales abordan esta realidad desde diferentes enfoques; los autores valoran de manera disímil esta nueva etapa de la humanidad. Algunos, positivamente, poniendo el eje en las posibilidades casi ilimitadas que presenta y en la apertura y democratización de los procesos sociales; otros, en términos críticos, cuando no apocalípticos, por la degradación moral, el debilitamiento de lazos sociales, la consolidación del pensamiento único ${ }^{4}$.

Así, por ejemplo, quienes realzan las bondades de la posibilidad infinita de comunicaciones y acceso a la información, se refieren a esta época como la sociedad de la información, realzando las posibilidades que las nuevas tecnologías abren para la humanidad 5 .

Desde otra perspectiva, el filósofo italiano Gianni Vattimo ${ }^{6}$, al analizar la función de la información en estos tiempos, expresa que, además del final del colonialismo y del imperialismo, ha habido otro factor decisivo para el advenimiento de la posmodernidad: la irrupción de la sociedad de la comunicación. La lógica del mercado de la comunicación implica que "todo, en cierto modo, venga a ser objeto comunicación", por lo que todo es materia de interpretaciones. Hemos entrado en una especie de 'babel informativa, donde la comunicación y los medios adquieren un carácter central. Es el paso del pensamiento fuerte, metafísico, al pensamiento débil. Las ideas de la posmodernidad y del pensamiento débil es-

FUKUJAMA, Francis (1994). El fin de la historia y el último hombre. Barcelona: Planeta.

MCLUHAN, Marshall (1985). Guerra y Paz en la Aldea Global. Barcelona: Planeta- DeAgostini.

BAUMAN, Zygmunt, Modernidad Líquida, Trad. de Mirta Rosenberg en colab. con Jaime Arrambide Squirru, $1^{\mathrm{a}}$. Ed., $8^{\mathrm{a}}$. Reimp. Buenos Aires: Fondo de Cultura Económica, p. 34: "La completitud es siempre futura, y los logros pierden su atractivo y su poder gratificador en el mismo momento de su obtención",

4 V.g. BAUMAN, Zygmunt (2007). Miedo líquido. La sociedad contemporánea y sus temores. Trad. de Albino Santos Mosquera. Barcelona: Paidós, Cap. 4, p. 125 y ss.

5 Para una introducción a los problemas sociales, económicos, jurídicos, culturales, derivados de la sociedad de la información: NEGROPONTE, Nicholas (1995). Ser Digital. Buenos Aires: Atlántida; BARRET, Neil (1998). El Estado de la Cibernación. España: Flor del Viento. SANCHEZ BLANCO, Angel (2000). Internet, Sociedad, Empresa y Poderes Públicos. España: Comares (con un rico repaso acerca de los debates generados en la sociedad española en torno a esta cuestión); LESSIG, Lawrence (1999). Code and Other Laws of Cyberspace. EEUU: Basic Books (quien plantea un oscuro futuro por la dominación de las redes por las grandes corporaciones). En Argentina: SARRA, Andrea Viviana (2000). Comercio Electrónico y Derecho. Parte Primera. Buenos Aires: Astrea.

6 VATTIMO, Gianni, “Posmodernidad ¿Una sociedad transparente?”. En: VATTIMO, Gianni y O. (1994). En Torno a la Posmodernidad. Anthropos Editorial, p. 9. 
tán estrechamente relacionadas con el desarrollo del escenario multimedia, con la toma de posición mediática en el nuevo esquema de valores y relaciones y con la influencia de los medios en las determinaciones sociales y políticas. Ponemos de resalto esta idea, las que nos será útil a la hora de analizar la situación del derecho de daños en la actualidad.

4. - Los anteriores son sólo ejemplos de cómo la posmodernidad ha influido de manera decisiva en todos los ámbitos del pensamiento, el que se encuentra en la búsqueda de un nuevo modelo explicativo de la nueva y compleja realidad.

$\mathrm{Si}$ bien, contemporáneamente, asistimos a una instancia de transformaciones, impulsada por el reposicionamiento geopolítico con posterioridad al 11 - S, por los movimientos globalifóbicos y altermundistas, por el resurgimiento de populismos, por la crisis mundial del capitalismo iniciada hacia fines de 2008 y con final imprevisible, la sustancia de esta nueva sociedad permanece incólume, así como su caracterización como "sociedad del riesgo".

\section{II.- LA SOCIEDAD DEL RIESGO.}

1.- Fue Urilch Beck ${ }^{7}$ quien acuñó la frase "Sociedad del riesgo" para caracterizar a los tiempos post-industriales o de la segunda modernidad, poniendo énfasis en la existencia creciente de amenazas a las personas, los bienes, la naturaleza, en definitiva a la subsistencia misma del planeta y de la humanidad.

Los riesgos proceden de una sobreproducción industrial, son globales y sus causas son modernas. "Son un producto global de la maquinaria del progreso industrial y son agudizados sistemáticamente con su desarrollo ulterior", dice Beck ${ }^{8}$.

"La modernidad es una cultura del riesgo (expresa Giddens ${ }^{9}$ ), la evaluación de los riesgos invita a la precisión, y también a la cuantificación, pero por su propia naturaleza es imperfecta. Dado el carácter móvil de las instituciones modernas, unido a la naturaleza mutable y frecuentemente controvertida de los sistemas abstractos, un buen número de criterios fijos de riesgo, de hecho, hacen gala de numerosos imponderables".

La modernidad reduce riesgos totales en ciertas áreas y modos de vida, sin embargo, al mismo tiempo, introduce nuevos parámetros de riesgo desconocidos totalmente, o en su mayor parte, en épocas anteriores.

\section{2.- Según Beck ${ }^{10}$ : (a) Estos ries-} gos causan daños sistemáticos y a menudo irreversibles, suelen permanecer invisibles y se basan en interpretaciones causales, por lo que sólo se esta- blecen en el saber (científico o anticientífico) de ellos, y en el saber pueden se transformados, ampliados o reducidos, dramatizados o minimizados, por lo que están abiertos en una medida especial a los procesos sociales de definición. (b) Los riesgos de la modernización afectan más tarde o más temprano también a quienes los producen o se benefician con ellos. (c) La expansión de los riesgos no rompe en absoluto con la lógica del desarrollo capitalista, sino que más bien la eleva un nuevo nivel... Se puede calmar el hambre y satisfacer las necesidades, pero los riesgos de la civilización son un barril de necesidades sin fondo, inacabable, infinito, autoinstaurable. (d) Lo que hasta el momento se había considerado apolítico se vuelve político: la supresión de las causas en el proceso de industrialización mismo.

"Ahí queda claro de una manera ejemplar de qué se trata propiamente en la disputa pública sobre la definición de los riesgos: no sólo de las consecuencias para la salud de la naturaleza y del ser humano, sino de los efectos secundarios sociales, económicos y políticos de estos efectos secundarios".

3.- Desde una perspectiva más amplia, Gonzalo Sozzo ${ }^{11}$ realiza una interesante descripción de los riesgos a los que la humanidad se ve expuesta, a los fines

BECK, Ulrich (2006), La Sociedad del Riesgo. Barcelona: Paidós.

Op. cit., p. 29 y ss.

GIDDENS, Anthony, “La Modernidad desmembrada y ambivalencia”. En: A. Giddens, Z. Baumann, N. Luhmann, U. Beck (1996). Las consecuencias perversas de la Modernidad. Josetxo Beriain Com., Anthropos Editorial, p. 33.

10 BECK, Ulrich, Op. cit., loc. cit.

11 SOZZO, Gonzalo (2007), “Los riesgos como problemas”. En: SOZZO, Gonzalo (Coordinador). El gobierno de los riesgos. Santa Fe: Universidad Nacional del Litoral. 
de determinar las vías para acometer su prevención. "Riesgos culturales consisten en la pérdida de las identidades y la memoria...Los riesgos ambientales son también una importante especie de riesgos en los cuales la amenaza consiste en el deterioro del medioambiente y la ocurrencia de catástrofes...Los denominados riesgos sociales tienen su propia identidad y constituyen un ámbito de estudios específicos. Aquí la amenaza consiste en la pérdida del trabajo y la ausencia de ingresos en la ancianidad...Existen también riesgos económicos y financieros; es el caso del colapso de los mercados globales...Un grupo de riesgos que pueden ser estudiados como tales son los "riesgos políticos" consistentes en el advenimiento de totalitarismos, dictaduras y redes de terrorismo...No es menos importante el sector de los riesgos personales, por ejemplo, sufrir un accidente cotidiano, no tener salud o alimentos. Finalmente, pueden individualizarse los denominados "riesgos científico-tecnológicos", que no son otros que los producidos por el desarrollo de la ciencia y las tecnologías y que son estudiados por los sciences studies que, a partir de la reflexión crítica acerca de la ciencia y sus derivados, procuran recorrer el camino de la humanización de la ciencia....". Es el campo jurídico el destino de una regulación de este tipo de riesgo".

2.- La prevención como necesidad en la sociedad del riesgo.

Si los daños son universales e irreversibles, la mirada se pone, entonces, en la necesidad de prevenir, de atacar las causas.

Mas la tarea está plagada de obstáculos. Las causas son invisibles y muchas veces desconocidas. 0 conocidas y ocultadas.

La ciencia, que produce el riesgo, es la encargada también de patentizarlas. ¿Puede ser la ciencia neutral en esa tarea?.

Los riesgos tienen componentes científicos, pero también sociales. La definición social del riesgo cobra su importancia. No basta que los científicos dictaminen que una actividad no es riesgosa, si la comunidad la siente como tal (la oposición de la sociedad a las actividades mineras 0 instalación de industrias que se presumen dañinas, aunque no exista prueba sobre ello, constituyen ejemplos de esta aserción).

Beck $^{12}$, al referirse a la postura que la noción de producto riesgoso proviene exclusivamente de las ciencias, expresa: "Aquí tenemos un error de categorías: un análisis de las sustancias nocivas basado en la naturaleza y en el producto no está en condiciones de responder a la pregunta de la falta de peligro, o al menos no lo está mientras el "peligro" y la "ausencia de peligro" tengan algo que ver con las personas que tragan y respiran", poniendo de resalto la noción subjetiva de riesgo.

\section{III.- EL DERECHO DE DAÑOS FREN- TE A LA SOCIEDAD DEL RIESGO.}

\section{1.- La transformación del de- recho de daños}

En el derecho de daños los modelos teóricos se actualizan para describir la nueva realidad y diseñar las herramientas adecuadas para el fin ${ }^{13}$.

Ante una sociedad sujeta a riesgos globales, invisibles, indeterminables, irreversibles, el modelo de la responsabilidad civil de los códigos del siglo diecinueve es insuficiente.

Del paradigma de los daños individuales, que puso su mira sólo en los partícipes del hecho ilícito, se pasa a otro modelo, en el que se consideran los intereses colectivos involucrados y sus modos de defensa. Se legitiman las agrupaciones de personas vinculadas por el mismo grupo de intereses en riesgo.

Se actualiza la noción de autoría; se pasa de la autoría individual a la colectiva.

Las reglas procesales se aggiornan para reglar el juzgamiento de los daños masivos, a través del proceso colectivo, y se articulan procedimientos urgentes para prevenir el daño.

Los sistemas son tan complejos, que para la explicación de los resultados se transita del modelo de la causalidad necesaria (determinación causal), al de la causalidad probable (determinación probabilística), o directamente al de la deter-

BECK, Ulrich. Op. cit., p. 39.

13 Las ideas esbozadas son desarrolladas con amplitud, profundidad y lucidez por ALTERINI, Atilio, en: "Rumbos actuales del derecho de daños", La Ley 2008-E, 1295 - RCyS2008, 301. 
minación normativa de la causa, alejándose de la explicación naturalística de los orígenes de los daños ${ }^{14}$.

El nuevo modelo se instala en determinados ámbitos. El derecho ambiental y el derecho del consumo son las puntas de lanza de las nuevas ideas. Pero las ideas se expanden al sistema todo.

\section{2.- Las funciones del derecho de daños.}

Ante daños irreversibles, el objetivo es evitar antes de reparar. El individuo ya no se conforma con buenas indemnizaciones; un mutilado, quien perdió a un ser querido, o fue difamado públicamente hubiese preferido no haber sido lesionado. La sociedad no soporta ya la exposición a fuentes contaminantes de su ambiente o al consumo de productos que pongan en peligro su salud.

Entonces, se actualizan también las bases teóricas sobre las funciones del derecho de daños; las tradicionales subsisten, pero actualizadas.

La función reparatoria se expande, para abarcar cada vez más intereses y con instrumentos más sofisticados de reparación. A mayores posibilidades de afrontar reparaciones, mayores son los cuidados que adoptan los posibles dañadores.
La función sancionatoria, tradicionalmente vedada al derecho de la responsabilidad civil, aparece nuevamente como una herramienta útil para sus fines actualizados.

La disuasión -íntimamente vinculada a la sanción y a la reparación- se muestra eficaz si los instrumentos sancionatorios 0 reparatorios inciden "a tal punto sobre el patrimonio del agente que lo induce a no cumplir el acto dañino o a ejercitar actividades que envuelven una ostensible reducción del margen de riesgo" ${ }^{\prime \prime}$.

En este marco, los daños punitivos, incorporados en el año 2008 a la legislación del consumo argentina, es una herramienta eficaz en la función disuasoria atribuida a la provincia de la responsabilidad civil.

\section{3.- La función preventiva (impeditiva) del derecho de daños.}

Mas en los últimos desarrollos de la responsabilidad civil se ha puesto el acento en la función preventiva del derecho de daños, con un perfil diferente a la finalidad preventiva que las herramientas reparatorias, sancionatorias o disuasorias (actualizadas a estos tiempos), pueden perseguir.

Al hacerse referencia a la función preventiva se alude a la necesidad ineludible de actuar con acciones específicas de prohibición de las actividades posiblemente dañosas. Preferimos llamar a esta tarea, función impeditiva del derecho de daños.

En principio, se habló de pasar de un sistema de prevención general (general deterrence) a uno de intervención legislativa limitada a determinados sectores (specific deterrence) a fin de desarticular la ocurrencia de un número de daños tan alto que constituiría un peligro para la misma sociedad ${ }^{16}$.

Mas la definición legislativa parece insuficiente, ante la imperceptibilidad de las causas generadoras y su constante mutación.

Entonces el modelo de prevención se extiende y las competencias se acumulan. Ya no es sólo el legislador quien puede impedir o regular las actividades posiblemente dañosas. $\mathrm{El}$ juez aparece como un nuevo actor en el conflicto.

\section{4.- El juez en la función impe- ditiva.}

El juez es puesto en el centro de la escena y se le imponen medidas positivas de evitación del daño.

El art. 4 de la ley general del ambiente de la Argentina expresa: "Principio precautorio:

14 PEREZ BARBERA, Gabriel (2006). Causalidad, Resultado y Determinación. Buenos Aires: Ad Hoc, 2006, p. 83: “....realizamos hipótesis causales no sólo porque ellas son posibles, sino porque son necesarias y excluyentes de toda otra clase de hipótesis. En este ámbito, hipótesis no causales serían inmediatamente dejadas de lado por no tener poder explicativo y resultar fácilmente refutables o falsables: bastará una serie finita pero suficientemente prolongada de experiencias sin ningún resultado adverso para demostrar que es seguro -y no solamente probable, que la piedra caerá. Con relación al segundo ámbito (al determinado estadísticamente) ocurre la inversa: allí las variables-datos intervinientes son tantas... que centrar la explicación en una sola de ellas resultaría temerario...".

15 ALPA, Guido (2001). Responsabilidad Civil y Daño. Traducción a cura de Juan Espinoza Espinoza. Lima: Gaceta Jurídica, p. 75.

$16 \quad$ ALPA, Guido. Op. cit., p. 77. 
Cuando haya peligro de daño grave o irreversible, la ausencia de información o certeza científica no deberá utilizarse como razón para postergar la adopción de medidas eficaces, en función de los costos, para impedir la degradación del medio ambiente.

La ley habla de peligro y no de riesgo ${ }^{17}$.

En la teoría de los riesgos se suele distinguir entre amenaza y riesgo. Una amenaza es todo aquello que tenga una posibilidad o probabilidad de ocurrir, como causante de daño, y el riesgo es el producto de la ocurrencia de la amenaza y su consecuencia. Desde un punto de vista probabilístico, una amenaza no puede ser considerada un riesgo sin al menos un hecho en que se haya producido el daño. Si se acepta esta distinción como útil, la prevención, en la fase actual, trabaja en base a amenazas, y no a riesgos.

El juez deberá trabajar ahora sobre bases mucho menos sólidas. ¿Quién determina la existencia de peligro de daño grave o irreversible -en la terminología de la ley general de ambiente-, si no existe información o certeza científica suficiente? ${ }^{18}$.

Aparece con fuerza el concepto de construcción social del peligro $^{19}$. E irrumpen los medios de comunicación como vehículos de intereses.

El juez es arte y parte, pues debe decidir sobre cuestiones que les son propias. Los daños ya no son de otros, no decide sobre la suerte de un peatón embestido por un automóvil, ni sobre la justicia de un contrato del cual no formó parte. Resuelve sobre aspectos que le incumben, pues los riesgos o peligros les son propios; y también sobre los efectos secundarios de la prevención del daño: se lo evita, pero también se influye sobre el destino de quienes se perjudican con la evitación de los daños (el de los operarios y sus familiares, por ejemplo, ante el cierre de una fábrica). Es que, en estos casos, la hipótesis causal que debe formular el juez para tomar la decisión impeditiva sólo podrá validarse, quizá, cuando la medida precautoria se haya efectivizado y, tal vez, mostrado falsa ${ }^{20}$. No es tarea fácil la que le cabe a los jueces en estos tiempos.

\section{5.- La prevención del daño en el Proyecto de Código Civil y Comercial de 2012.}

El Proyecto de Código Civil y Comercial para la Argentina, en discusión en el Parlamento al momento de entregar este artículo (setiembre 2014), reconoce de manera expresa la función preventiva de las reglas del derecho de daños, articulando reglas para su actuación.

El artículo 1710 determina el deber de toda persona de evitar, en cuanto de ella dependa, causar un daño o disminuir su magnitud y de no agravarlo si ya se produjo. El artículo 1711 habilita la acción procesal preventiva frente a cualquier acción u omisión que, previsiblemente, pueda producir un daño, su continuación o agravamiento, legitimando a cualquiera que acre-

17 MORALES LAMBERTI, Alicia y NOVAK, Aldo (2005). Instituciones de Derecho Ambiental. Córdoba: M.E.L. Editor, p. 111: “La aplicación del principio precautorio supone: a) La identificación de efectos potencialmente peligrosos que se derivan de un fenómeno, un producto o un proceso; y b) Una evaluación científica de los riesgos que debido a la insuficiencia de los datos, a su carácter no concluyente o a su imprecisión, no permite determinar con una certeza suficiente el riesgo en cuestión.

18 MORALES LAMBERTI, Alicia y NOVAK, Aldo, Op. cit., p. 112: “La Evaluación de Riesgos se compone de cuatro elementos, a saber: a) identificación del peligro; b) caracterización del peligro, c) evaluación de la exposición y d) caracterización del peligro. Los límites del conocimiento científico pueden afectar a cada uno de estos componentes...Las autoridades públicas responsables deben adoptar las medidas de gestión de riesgo, a tenor de una apreciación "política" del grado de protección deseado... Igualmente las medidas que se adopten, presuponen el estudio de las ventajas y de las cargas derivadas de la acción o de la falta de acción ("en función de los costos"). Dicho estudio tendrá en cuenta los costos sociales y medioambientales, así como la aceptación que pueden suscitar entre la población las distintas opciones posibles, e incluirá, cuando sea factible, un análisis económico pero siempre concediendo carácter prioritario a las exigencias vinculadas a la protección de la salud pública...".

19 HILGENDORF, citado por PEREZ BARBERA, Gabriel (2006), Causalidad, Resultados y Determinación. Buenos Aires: Ad-Hoc, p. 44, expresa: "La concepción según la cual el examen causal constituiría una operación puramente cognitiva no es consistente. Antes bien, la exacta delimitación del resultado cuya causalidad debe explicarse presupone ya decisiones de quien ha de aplicar el derecho".

20 MORALES LAMBERTI, Alicia y NOVAK, Aldo, Op. cit., p. 113, expresan que la aplicación del principio genera controversias, por lo cual se lo ha intentado relativizar llevándolo a nivel de "enfoque" o de "guía" de actuación. Entre los temas controvertidos que marcan se encuentran el de determinar el umbral de "probable daño" o "daño serio e irreversible" para su determinación, la noción de "costo-beneficio" o "riesgo-beneficio" y el estado de los conocimientos científicos y técnicos y su incertidumbre. 
dite un interés razonable. El artículo 1712 regla el contenido posible de la Sentencia preventiva, el que puede consistir en obligaciones de dar, hacer o no hacer, en forma provisoria o definitiva, ponderando los criterios de menor restricción posible y de medio más idóneo para asegurar la eficacia en la obtención de la finalidad.

\section{HaCia un derecho de daños} CONSOLIDADO

Bauman ${ }^{21}$ instaló la idea de la modernidad líquida, utilizan- do la metáfora de los fluidos, carentes de formas, para describir la sociedad en la que vivimos, en la que los códigos y conductas que se podían elegir como puntos de orientación estables, y por los cuales era posible guiarse, se diluyen rápidamente y no soportan el paso del tiempo.

La situación del derecho de daños frente a los riesgos se adecua a aquella metáfora. El modelo teórico de soluciones posibles, y las reglas pertinentes, están, de algún modo, todavía en estado líquido, buscando algunos modos de condensación para otorgarle solidez $y$, por ello, permanencia.

El estado sólido no será hallado con actitudes dogmáticas o autoritarias; sólo una posición crítica frente a los problemas es el camino adecuado en la búsqueda de las soluciones que la sociedad requiere a esta disciplina.

Esta es la tarea que incumbe al derecho de daños y su compromiso.

1 Op. cit. 
